Hydrobiologia

November 2019, Volume 845, Issue 1, Pages 95-108

http://dx.doi.org/10.1007/s10750-018-3736-3

http://archimer.ifremer.fr/doc/00453/56476/

(c) Springer Nature Switzerland AG 2018

\title{
Size-effect, asymmetry, and small-scale spatial variation in otolith shape of juvenile sole in the Southern North Sea
}

\author{
Delerue-Ricard Sophie 1, 2, ${ }^{*}$, Hanna Stynen ${ }^{1}$, Barbut Léo ${ }^{1,3}$, Morat Fabien ${ }^{4,5}$, Mahé Kelig ${ }^{6}$, \\ Hablützel Pascal ${ }^{1}$, Hostens Kris ${ }^{2}$, Volckaert Filip ${ }^{1}$
}

\begin{abstract}
${ }^{1}$ Laboratory of Biodiversity and Evolutionary Genomics (LBEG), KU Leuven, Charles Deberiotstraat 32, Box 2439, 3000 Louvain, Belgium

2 Institute for Agricultural and Fisheries Research, Ankerstraat 1, 8400 Ostend, Belgium

${ }^{3}$ Operational Directorate Natural Environment (OD Nature), Royal Belgian Institute of Natural Sciences (RBINS), Gulledelle 100, 1200 Brussels, Belgium

4 PSL Research University: EPHE-UPVD-CNRS, USR3278 CRIOBE, 66860 Perpignan, France

${ }^{5}$ Laboratoire d'Excellence «CORAIL», BP 1013 Papetoai, 98729 Moore'a, French Polynesia

6 Ifremer, Fisheries Laboratory, Sclerochronology Centre, 150 quai Gambetta, BP 699, 62321 Boulogne, France

* Corresponding author : Sophie Delerue-Ricard, email address : Sophie.DelerueRicard@kuleuven.be
\end{abstract}

\begin{abstract}
:
While otolith shape analysis can provide a valuable tool for discriminating between fish populations, factors which may influence otolith shape, such as the effect of size, directional asymmetry in growth, and local environmental conditions, are often unknown. Here, we analyzed differences in otolith shape across three size classes of age-0 common sole Solea solea L. from nursery grounds off the Belgian coast and in the Wadden Sea. Across size classes, form-factor decreased and roundness remained consistently high in both nursery grounds, while ellipticity increased in the Belgian nursery. Directional asymmetry between left and right otoliths measured by Fourier coefficients accounted for 0.96 and $7.2 \%$ of the variance when comparing otoliths overall, and for each size class, respectively. Within the Belgian nursery, results were consistent across sampling years and locations. In addition, otolith shape was marginally different between nursery grounds, but highly variable within nursery grounds. A small divergent group, which seems partly related to fish size, was noted at both spatial and temporal scales. Based on these results and before embarking on a study of population structure using otolith shape in age- 0 common sole, we recommend testing for directional asymmetry and fish size effects across the entire region of interest.
\end{abstract}

Keywords : Early-life stages, Fourier coefficients, Nursery ground, Otolith shape, Small-scale spatial structure 


\section{Introduction}

Coastal ecosystems play a key role as nursery grounds for juvenile fish (Costanza et al., 1998) because of their high productivity. However, coastal nursery grounds have a discontinuous distribution, and experience increasing fragmentation due to anthropogenic pressures, which can result in changes of metacommunity diversity and dynamics (Jung et al., 2017). In addition, habitat heterogeneity within nursery grounds may influence the spatio-temporal dynamics of fish populations on a small spatial scale (Le Pape et al., 2003).

Various indirect methods are available to assess the spatial population dynamics of the earlylife stages of marine fish, such as modelling of larval transport, comparison of parasite communities, analysis of genetic differentiation, chemical composition and shape of fish otoliths, or tagging of the late juvenile stages (Cadrin et al., 2014; Koubbi et al., 2006; Pawson \& Jennings, 1996; Neves et al., 2018). Despite the diversity of methods, population structure and connectivity patterns between and within nursery grounds remain challenging to evaluate (Kaplan et al., 2016). Moreover, each tool may integrate information at specific, yet different spatial and temporal scales. Biophysical modelling of larval transport and otolith shape variation focus on 'ecological' time scales (Lacroix et al., 2013; Thorrold et al., 2001), while genomic tools have been applied to measure population structure over both short 'ecological' and longer 'evolutionary' time scales (Pinsky et al., 2017). Yet, advanced genomic tools work best with extensive genomic background information on the species of interest and well-preserved DNA.

Otoliths are calcified structures residing in the inner ear of fish, growing with the constant deposition of successive calcium carbonate layers. As they grow, otoliths incorporate time-delimited information that can be used to describe the development and ambient environmental conditions experienced by the individual. In addition, otolith shape is a useful and well-established tool to discriminate between species and stocks (Campana \& Casselman, 1993). However, ontogenetic development affects otolith shape through changes in growth and metabolism, especially during 
sexual maturity (Cardinale et al., 2004; Hüssy, 2008; Mérigot et al., 2007). During the early-life stages, otoliths evolve from circular to more complex shapes (Lagardère \& Troadec, 1997; Hüssy, 2008), which may limit the utility of otolith shape as stock marker for immature fish or fish of different age classes. Moreover, left and right otoliths may be different, i.e. directionally asymmetrical, particularly in flatfishes (Mille et al., 2015). Environmental and anthropogenic pressure may cause stress-induced changes such as increased levels of directional asymmetry (Gagliano \& McCormick, 2004), which is disadvantageous because it interferes with hearing and orientation (Anken et al., 2002; Lychakov \& Rebane, 2005).

Most studies have compared intraspecific differences in otolith shape either over large distances (>500 km e.g. Vieira et al., 2014), across oceanographic barriers (Tuset et al., 2003) or between habitats (Morat et al., 2014; Vignon \& Morat, 2010). It is not yet clear what can be learned from otolith shape at small spatial scales and in the absence of strong oceanographic barriers. Here we used otolith shape analysis to investigate small-scale nursery structure of the flatfish sole Solea solea (Linnaeus, 1758; Soleidae) in the shallow subtidal of the Southern North Sea. Sole is less abundant than European plaice (Pleuronectes platessa L.) or dab (Limanda limanda L.) in the study area, but it has a high commercial value, contributing to important regional and local demersal fisheries. To date, connectivity patterns between spawning and nursery grounds remain unclear (Burt \& Millner, 2008; Lacroix et al., 2013). In the Southern North Sea, sole displays peak spawning from April to June. After hatching the pelagic larvae drift for $\sim 1$ month in the water column before settling in a nursery (Russell, 1976; van der Land, 1991). Genetic data from adult sole suggest isolation by distance along the Atlantic coast, and weak population structure within the Southern North Sea (Cuveliers et al., 2012; Diopere et al., 2018), with a mean dispersal distance estimated at $150 \mathrm{~km}$ (Kotoulas et al., 1995; Lacroix et al., 2013). Within the nursery grounds, age-0 sole travel shorter distances, between 10 and $30 \mathrm{~km}$ (Le Pape \& Cognez, 2016). Nevertheless, small-scale spatio-temporal variation in connectivity between and within nursery grounds has, to the best of our knowledge, not been investigated empirically. The degree of isolation between and within nursery grounds may be estimated from the variation in otolith shape. Being able 
to delineate the smallest level of spatial resolution is an important step to measure connectivity and to better understand recruitment patterns.

In the current study we addressed three key questions to determine whether otolith shape can be used to assess small-scale spatial patterns in juvenile flatfish: (1) what is the effect of fish size on otolith shape; (2) what is the effect of directional asymmetry between left and right otoliths, and (3) whether is there spatio-temporal variation in the otolith shape of age-0 sole.

\section{Material and methods}

We investigated variation in otolith shape over two years and at two spatial scales within the dispersal range of sole larvae, to better understand the resolution of otolith shape variation between and within nursery grounds in the Southern North Sea. Juvenile sole were sampled at the regional scale (between nursery grounds, $400 \mathrm{~km}$ distance) from the Belgian and Wadden Sea nursery grounds in 2014 (NL2014 and BE2014). Juvenile sole were sampled at the local scale (within nursery) from the eastern and the western shallow subtidal coastal zones of the Belgian nursery in 2013 and 2014 (BE2013 and BE2014, $40 \mathrm{~km}$ distance between coastal zones). The discriminatory power of otolith shape was tested using Fourier coefficients and shape indices (see further). In addition, asymmetry between left and right otoliths and correlations between the shape indices and fish size were estimated using the combined data from all fish from the three datasets (BE2013, BE2014, NL2014).

Sample collection

Juvenile sole were sampled off the Belgian coast from late August to late September in 2013 and from mid-September to mid-October in 2014 (Figure 1; Table 1) and at two stations in the Wadden Sea in September 2014. At each site, specimens were collected by beam trawling either on board of RV Simon Stevin (B-FishConnect project campaign), RV Belgica (Belgian Demersal Young Fish Survey, DYFS) or RV Stern (Dutch DYFS). Sea surface temperature was measured at each site at the time of collection. Each 
122 fish was measured to the nearest $\mathrm{mm}$ (Standard Length, SL). Sagittal otoliths were extracted from a

123 total of 314 individuals ranging from 52 to $102 \mathrm{~mm} \mathrm{SL}$. Finally, each otolith was cleaned, sonicated, and then stored dry in plastic vials. For this study, age-0 sole were used. Fish age was confirmed by the absence of an annual ring in the otolith. To assess variation in otolith shape associated with fish size, the 314 individuals were divided into three standard length size-classes, L1 (52-76 mm, $\mathrm{m}=105), \mathrm{L} 2$ $(76-82 \mathrm{~mm}, \mathrm{n}=105)$ and L3 $(82-102 \mathrm{~mm}, \mathrm{n}=104)$.

Otolith shape indices and Fourier coefficients

Left and right sagittae were placed on a microscope slide with a black background, positioned with the sulcus acusticus oriented towards the observer and the posterior side oriented to the top. External transmitted light sources were used and adjusted to illuminate the otoliths. High-contrast images were produced using an Olympus ColorView digital microscope camera linked to an Olympus BX51 microscope (20x magnification). Images were then processed with the TNPC 7 software ('Digital Processing for Calcified Structures'; www.tnpc.fr) to extract the following morphometric parameters: surface area of the otolith $\left(A_{o}\right)$; otolith perimeter $\left(P_{0}\right)$; maximum length $\left(L_{0}\right)$; and width $\left(O_{w}\right)$ to the nearest $10^{-2} \mathrm{~mm}$. Based on these measurements, form-factor, roundness, circularity, rectangularity, and ellipticity were calculated as in Tuset et al. (2003). Form-factor estimates surface area irregularity and has a maximal value of one in the case of a perfect circle. Roundness and circularity describe the proximity of shape to a circle and have minimal values of one and 12.57 , respectively. The closer both indices approach the minimal value, the closer the shape of the otolith is to a perfect circle. Rectangularity gives the proportion of the length and width with respect to the area and has a maximal value of one in case of a perfect square. Ellipticity describes the proportion of change in the different axes (Tuset et al., 2003).

In addition to the use of shape indices, otolith contours were described by Elliptic Fourier Descriptors (EFDs) which were obtained with TNPC 7 software. For each otolith, the first 99 elliptical 
147 Fourier harmonics were extracted and normalised with respect to the first harmonic. Hence, they were 148 invariant to otolith size, rotation and starting point of the contour description (Kuhl \& Giardina, 1982).

149 To determine the number of elliptical Fourier harmonics required to reconstruct the otolith outline, the Fourier Power (FP) spectrum was calculated for each individual otolith. For the $\mathrm{n}^{\text {th }}$ harmonic,

151

152

153

154

155

156

157

158

159

160

161

162

163

164

165

166

167

168

169 Fourier Power is given by the equation:

$F P_{n}=\left(A_{n}{ }^{2}+B_{n}{ }^{2}+C_{n}{ }^{2}+D_{n}{ }^{2}\right) / 2$,

where $A_{n}, B_{n}, C_{n}$ and $D_{n}$ are the Fourier coefficients of the $\mathrm{n}^{\text {th }}$ harmonic.

Cumulative Fourier Power $\left(\mathrm{FP}_{\mathrm{c}}\right)$ was calculated by summing the Fourier power of each harmonic:

$F P_{c}=\sum_{1}^{n} F P_{n}$

The number of harmonics was chosen such that the mean cumulated FP reached $99.99 \%$; hence shape was reconstructed at 99.99\% (Mérigot et al., 2007; Gonzalez-Salas \& Lenfant, 2007). The first harmonic was not considered for further analysis (except for reconstructing average shape), because it had already been used for normalization, and because it would dominate shape reconstruction and mask the information derived from the other harmonics (Crampton, 1995).

\section{Statistical analysis}

First, a pilot experiment was conducted to assess the consistency of our methodology with regard to otolith position and lighting. Ten randomly chosen otoliths were repositioned and four replicate pictures were taken. A dendrogram analysis was performed to test the extent of differences between images of the same otolith and differences between images of different otoliths.

Multi-collinearity between shape indices was assessed by Pearson correlation. Only form-factor, roundness and ellipticity were kept for further analyses. Shape indices were compared between length classes, the two nursery grounds, and sampling years. Differences in the mean values of shape indices 
between each size class and each dataset were assessed using non-parametric $k$-sample AndersonDarling tests under the null hypothesis that all samples originated from the same distribution.

Before analyzing asymmetry levels and spatio-temporal variation in the Fourier coefficients, Principal Component Analysis (PCA) was applied to the Fourier coefficients to avoid collinearity of shape descriptors, and to reduce the number of dimensions while retaining the majority of the variance (Rohlf \& Archie, 1984). Only PCs with eigenvalues higher than the mean of all eigenvalues were retained to remove Principal Components (PCs) associated with noise. Fourier coefficients were significantly correlated with fish size. Residuals of the PCs of Fourier coefficients have been used to remove the effect of fish size, as in Mahé et al. (2016).

Partial Redundancy Analysis (pRDA) tests were performed with the PCs of the Fourier coefficients as response variables to explore the effect of otolith side, between and within-nursery spatial variation, year, coastal region and Sea Surface Temperature (SST). Redundancy analysis is an extension of multiple regression analysis to multivariate response data (Legendre \& Legendre, 2012). In all pRDAs, SL was used to correct for fish size, and a permutation test was used to assess the significance of the explanatory variables. A pRDA was performed to test the effect of otolith side (left/right) on shape. To visualize and quantify differences between left and right otoliths, the average otolith shape of each side was also built by outline reverse Fourier transformation, as in Mille et al. (2015).

Dendrograms were produced by ascending hierarchical classification $(A H C)$ to verify the PCA clustering of individuals at the regional and local scales. AHC maximizes the similarities within clusters and differences between clusters of similar otolith shapes. To compute the AHC, the function 'HCPC' based on Ward's distance was used.

pRDA was also used to determine regional and local scale (between and within nursery) annual differences in otolith shape. We used multiple linear regressions to test at the regional scale the effect of nursery, sampling date, and SST on the Fourier coefficient PCs, and to test at the local scale the 
effect of year, coastal zone (eastern/western), and SST on the same PCs. We determined the variance explained by each explanatory variable. Only the left otoliths were used in the RDAs. Distribution of standard length was compared using a randomization test. All statistical analyses were performed using the ade4, FactoMineR, vegan and stats packages in the statistical environment $\mathrm{R}$ ( $\mathrm{R}$ Development Core Team, 2011).

The outlines of the mean Fourier coefficients (prior to size correction) were plotted as an overlay image to visualize differences in otolith shape between left and right otoliths. The same overlay was used to visualize differences between left otoliths of the Belgian and Wadden Sea nursery grounds, and between left otoliths of the two PCA clusters (Mille et al., 2015).

\section{Results}

Cluster analysis showed that Fourier coefficients extracted from replicated images of the same otolith were consistently grouped together and our measures were accurate (Supplementary Figure S1). Otolith form-factor, ellipticity and roundness were not redundant (Pearson correlation test, $P>0.05$ ) and were kept for further analysis. For each dataset (BE2013, BE2014 and NL2014), form-factor significantly decreased with increasing standard length (Figure 2a; Table 2). Only in the Belgian nursery ellipticity was significantly different between length classes for both sampling years (Figure 2b). Roundness was generally close to one and did not vary significantly between size classes or nursery grounds but varied between sampling years in the Belgian nursery (Supplementary Figure S2). In addition, otoliths sampled in 2014 off the Belgian coast were significantly more circular than in the Wadden Sea, and also significantly more circular and rounder than otoliths sampled in 2013 on the Belgian nursery as shown by form-factor variations (Table 2).

The Fourier coefficients differed significantly between left and right otoliths ( $n=314, P<0.01$ ). This directional asymmetry explained almost $6 \%$ of the variance (Table 3 ) and was spread homogeneously across the otolith outline (Figure 3a). Although the overall average directional 
asymmetry was quite small when all datasets and size classes were pooled ( $0.96 \%$ overall), asymmetry was much higher when each dataset and size classes were examined separately (mean asymmetry for each dataset was 7.2\%). Left otoliths of sole (blind side) were larger than right otoliths (eyed-side) and were thus kept for further analysis.

Among the 99 Fourier harmonics extracted to describe the left otolith contour, the first 22 harmonics explained more than $99.99 \%$ of the variance and were thus retained for multivariate analyses. Small differences in average shape (1.2\% overall) were visible between the Belgian and Wadden Sea nursery grounds based on the reconstructed average otolith shape (Figure 3b). The variance in otolith shape explained by fish size $(P=0.086$ and $P=0.004$ for NL-BE 2014 and BE 20132014, respectively) was removed (see Material and methods section Statistical analysis for more details). The first and second axes from a PCA comparing the Belgian and Wadden Sea nursery grounds in 2014 accounted for 30.2 and $28.6 \%$ of the total variance, respectively. At the local scale (within the Belgian nursery) in 2013 and 2014, the first and second PCs accounted for 31.8 and $28.6 \%$ of the total variance, respectively. Ten PCs had eigenvalues above the mean eigenvalue, and accounted for $91.0 \%$ of the variance when comparing shapes at both nursery grounds in 2014 , and $90.6 \%$ when comparing shapes in the Belgian nursery between years. Both PCA plots showed considerable variation in otolith shape both at the regional and local scale, and it was not possible to detect PCA clusters by nursery or by year (Figure 4a and 4b). However, two distinct clusters were observed at both geographical scales and during both sampling years based on the first two PCs. These clusters were also supported in both cases by clustering dendrograms (Supplementary Figure S3). A small number of fish, belonging to both the Belgian and Wadden Sea nursery grounds (Figure 4a) and both 2013 and 2014 Belgian samples (Figure 4b), clearly diverged in otolith shape. This divergent group of fish consisted of approximately $10 \%$ of the individuals from NL2014, $10 \%$ of BE2014 and $16 \%$ of the BE2013, independent of standard length size class. Shape diverged in two areas on both the posterior or anterior side of the otolith and accounted for $11.5 \%$ of shape variation (Figure 3c). For the 2014 dataset, fish from the divergent group were significantly longer ( $\mathrm{SL}: 72$ to $95 \mathrm{~mm}$ ) than those from the majority cluster (SL: 57 to $93 \mathrm{~mm}$ ) 
(Figure 5; randomization test for NL-BE 2014: $\mathrm{n}=141, \mathrm{~W}=1221, P=0.041$ ). In the Belgian nursery, the average SL of the divergent group was not significantly longer than that of the majority cluster for the local dataset (Figure 5; randomization test for $B E$ 2013-2014: $n=253, W=4258, P=0.525$ ).

Redundancy analysis (RDA) was used to correlate the observed pattern of otolith shape with potential explanatory variables (Table 3 ). At the regional scale, otolith shapes in the Belgian and Wadden Sea nursery grounds differed significantly, even though that difference was only marginally significant $(P=0.04)$ and explained less than $1 \%$ of the variance. At the local scale of the Belgian nursery, neither an effect of sampling year nor of coastal zone (eastern/western) on otolith shape was detected. Both SST and sampling date did not significantly explain variation in otolith shape, irrespective of the spatial scale considered.

\section{Discussion}

Analysis of otolith shape on age- 0 sole collected in the Southern North Sea revealed five interesting results. Otolith shape, as described by shape indices and Fourier coefficients, was influenced by fish size. Weak but significant directional asymmetry in otolith shape was observed between the left and right otoliths. Among-site variation in otolith shape was small but significant at the regional scale (Belgian vs. Wadden Sea nursery grounds, $400 \mathrm{~km}$ distance). Such variation was absent at the local scale (eastern vs. western coastal zones of the Belgian nursery, $40 \mathrm{~km}$ distance) and between two consecutive years (2013 vs. 2014).

\section{Impact of fish size and directional asymmetry on shape in age-0 sole}

Several confounding factors were taken into account before considering which factors drive spatial and temporal variation of otolith shape. First of all, a single age group (age-0 sole) was considered. Secondly, we corrected Fourier coefficients for fish size (Campana \& Casselman, 1993; Cardinale et al., 
2004; Mérigot et al., 2007). Thirdly, variation due to methodology and individual variability was successfully addressed in a pilot experiment focusing on positioning and lighting methods of the photography.

Adult otoliths tend to be more complex in shape than juvenile otoliths (Capoccioni et al., 2011; Morat et al., 2017). Directional asymmetry in shape, mass and chemical composition have been observed between the left and right otoliths in adult and juvenile flatfish but never quantified in juveniles (Mille et al., 2015; Mérigot et al., 2007). This study demonstrates that directional asymmetry is already present in age-0 flatfish. Our results suggest that asymmetry builds up over time because of differential growth between the larger otolith on the blind side vs. the smaller otolith on the eyed side. Still, the limited variation observed between both otolith sides supports Mille et al. (2015) suggestion of the presence of an evolutionary selection pressure against asymmetry to avoid negative effects on fish hearing and equilibrium.. Our study establishes that, similarly to adults (Mille et al., 2015), left and right otoliths should not be used interchangeably in shape analyses of juvenile sole. This lack of interchangeability is likely for all other analyses carried out on otoliths, such as chemical asymmetry (Morat et al., 2014). Moreover, fish size should always be accounted for because it affects otolith shape even in age-0 fish. Our results are consistent with Mapp et al. (2017), who showed that including size information increases the power of stock discrimination based on juvenile otolith shape. The formfactor decreased with increasing size in both nursery grounds and during both sampling years, while ellipticity increased in the Belgian nursery. Roundness did not vary significantly either with fish size or between nursery grounds. The only difference in roundness we could detect was in the Belgian nursery, where roundness was lower in 2013 than in 2014. Overall, roundness was higher than observed in Mediterranean samples (Mérigot et al., 2007), which might be due to higher growth rates in the Mediterranean Sea compared to the North Sea sole (Morat, 2011). In summary, we show that otoliths of age-0 sole in the Southern North Sea were relatively round, directionally asymmetrical, and that area irregularity increased during the first year of life. 
Small differences between nursery grounds

Our results show that we can detect variation in otolith shape at relatively small spatial scales. Overall, the average shape differed more between nursery grounds than between otolith sides, although these differences disappear when size classes are taken into account and asymmetry measured within each. This result suggests that differences between nursery grounds are size related. Assuming comparable environmental conditions at the Belgian and Wadden Sea nursery grounds (OSPAR, 2000), one might expect a comparable nursery ground environment impact on otolith shape, which we do not observe. Thus other factors, such as genetic background, spawning location and dispersal may also be important in influencing otolith shape (Cardinale et al., 2004; Capoccioni et al., 2011; Lombarte et al., 2003; Mapp et al., 2017). This observation is supported by the similar levels of variation in otolith shape between nursery grounds and between the two successive sampling years. Genetic levels are expected to vary only to a limited extent within the Southern North Sea, because sole exhibit an almost homogeneous population structure (Cuveliers et al., 2012; Diopere et al., 2018). At the same time, earlier microchemical studies point to a reduced mobility and site fidelity of age-0 sole in the Southern North Sea (Cuveliers et al., 2010; Le Pape \& Cognez, 2016). Differences in otolith shape and microchemistry between two 'adjacent' nursery grounds support some degree of natal site fidelity, which is not unexpected given the temporally stable location of the spawning grounds of sole.

A divergent group of age- 0 sole at both nursery grounds

We noticed two distinct groups of otolith shapes in both PCA analyses and clustering dendrograms. This result raises the question as to whether these individuals, representing 10 and $16 \%$ of all age- 0 sole screened respectively, experienced a somewhat different environment or have a different origin. Fish of the divergent group exhibited a larger size than most other fish. However, the divergent group was sampled across sampling dates (spanning over one month), suggesting that shape differences are not linked to age differences between individuals. 
ground and planktonic drift. According to the biophysical model of Lacroix et al. (2013), larvae arriving at the Belgian and Wadden Sea nursery grounds originate from the spawning grounds off the Belgian coast, the Eastern English Channel and the Thames Estuary. Between-year connectivity levels are comparable, although the relative proportions of source populations vary. Building on the results of the present study, other approaches would be required to identify larval origin. For example, spawning time can be estimated from otolith microstructure and used to back-calculate larval origin (Amara et in prep.). Additionally, otolith microchemistry is effective in resolving small-scale spatial differences. Based on otolith microchemistry, Cuveliers et al. (2010) were able to distinguish nursery grounds of sole from the Thames Estuary, Belgian coast, and Wadden Sea. However, chemical signatures of spawning grounds of sole in that area have yet to be explored. In summary, complementary information on otolith chemistry, biophysical modeling or a combination using the aforementioned techniques, should reveal the origin of spawning, and the dispersal pathways (Campana, 2005; Morat et al., 2014). Such information would contribute to a better understanding of the connectivity patterns of sole between spawning and nursery grounds.

The importance of spatial scale

Understanding local population dynamics is crucial, especially for coastal habitats, which are key nursery grounds for many marine species. Over the last decades changes in food webs and sheltering conditions provided by structuring benthos have dramatically affected nursery function along the North Sea coast (Jung et al., 2017; Rabaut et al., 2013; Van der Veer et al., 2011). We examined otolith shape across the Southern North Sea at a scale close to the average dispersal distance of sole $(150 \mathrm{~km}$, Kotoulas et al., 1995). Small, but significant differences were identified between two adjacent nursery 
in habitat characteristics between the eastern and the western coastal zones of the Belgian nursery, with mostly muddy to sandy sediments in the east and sandy to muddy sediments in the west (Van Hoey et al., 2004). Each sediment type harbors a specific macrobenthic assemblage (Degraer et al., 2008; Rabaut et al., 2013), with a distinct prey spectrum for sole and potential influence on otolith shape. However, starvation experiments suggest that food quantity could be more important than food type to determine otolith shape. Thus, if juvenile sole would be restricted to one coastal nursery ground or region within the Belgian nursery, the limited effect of food type on otolith shape could partially explain the absence of variation within the Belgian nursery (Cardinale et al., 2004; Gagliano \& McCormick, 2004; Hüssy, 2008).

In conclusion, small scale differences in otolith shape can be diagnostic and may play a role in population dynamic studies. During the first year of life of sole, otolith shape evolves from round to a more complex shape. Directional asymmetry between left and right otoliths is already present in age0 sole and has therefore to be taken into account in flatfish juveniles and adults alike. Despite a large variation in otolith shape, a subtle but significant difference was observed at a scale of $400 \mathrm{~km}$, i.e. the dispersal scale of sole, which is a promising finding for the study of small-scale spatial patterns. At the local scale (within nursery grounds), no significant shape differences were noted between the eastern and the western coastal zones of the Belgian nursery, nor between 2013 and 2014. However, a number of samples showing a divergent otolith shape, probably linked to fish size, was found on both nursery grounds in both successive years. Complementary studies on the integration of high resolution genotyping, elemental analysis of otoliths and biophysical modelling of early-life stages, are expected to provide additional evidence on the dispersal dynamics between spawning and nursery grounds. 
Special thanks to K. Vanhalst (Institute for Agricultural and Fisheries Research, ILVO), the crew of RV Simon Stevin and RV Belgica, L. Bolle (Wageningen Marine Research), the crew of RV Stern and the BFishConnect team for sampling. We are grateful to E. De Keyser, H. Christiansen, F. M. Heindler, F. Calboli (KU Leuven), B. Ernande (Ifremer), G. Lacroix (Royal Belgian Institute of Natural Sciences, RBINS), A. Vanden Bavière, J. Robbens (ILVO) and M. R. Siskey (Stony Brook University) for constructive comments. The B-FishConnect project was funded by the Research Foundation - Flanders (project number G.0702.13N). Thanks also to three anonymous reviewers, who provided many helpful comments.

\section{Data availability}

The datasets generated and analyzed during the current study are available from the corresponding author on reasonable request.

\section{References}

Amara, R., F. Lagardère, \& Y. Desaunay, 1993. Seasonal distribution and duration of the planktonic stage of Dover sole, Solea solea, larvae in the Bay of Biscay: an hypothesis. Journal of Fish Biology 43: $17-30$.

Anken, R. H., M. Beier, \& H. Rahmann, 2002. Influence of hypergravity on fish inner ear otoliths: I. Developmental growth profile. Advances in Space Research 30: 721-725.

Burt, G. J., \& R. S. Millner, 2008. Movements of sole in the southern North Sea and eastern English Channel from tagging studies (1955-2004). Science Series Technical Report. Cefas Lowestoft, 143: 144 
394

395

396

397

398

399

400

401

402

403

404

405

406

407

408

409

410

411

412

413

414

415

416

Cadrin, S. X., A. L. Kerr, \& S. Mariani (eds), 2014. Stock identification methods: applications in fishery science. Academic Press, Amsterdam.

Capoccioni, F., C. Costa, J. Aguzzi, P. Menesatti, A. Lombarte, \& E. Ciccotti, 2011. Ontogenetic and environmental effects on otolith shape variability in three Mediterranean European eel (Anguilla anguilla, L.) local stocks. Journal of Experimental Marine Biology and Ecology 397: 1-7.

Campana, S. E., 2005. Otolith elemental composition as a natural marker of fish stocks. In Stock identification methods (eds), Academic Press, Burlington: 227-245

Campana, S. E., \& J. M. Casselman, 1993. Stock discrimination using otolith shape analysis. Canadian Journal of Fisheries and Aquatic Sciences 50: 1062-1083.

Cardinale, M., P. Doering-Arjes, M. Kastowsky, \& H. Mosegaard, 2004. Effects of sex, stock, and environment on the shape of known-age Atlantic cod (Gadus morhua) otoliths. Canadian Journal of Fisheries and Aquatic Sciences 61: 158-167.

Costanza, R., R. d’Arge, R. De Groot, S. Farber, M. Grasso, B. Hannon, K. Limburg, S. Naeem, R. V. O’Neill, J. Paruelo, R. J. Raskin, P. Sutton, \& M. van den Belt, 1998. The value of ecosystem services: putting the issues in perspective. Ecological Economics 25: 67-72.

Crampton, J. S., 1995. Elliptic Fourier shape analysis of fossil bivalves: some practical considerations. Lethaia 28: 179-186.

Cuveliers, E., A. Geffen, J. Guelinckx, J. Raeymaekers, J. Skadal, F. Volckaert, \& G. Maes, 2010. Microchemical variation in juvenile Solea solea otoliths as a powerful tool for studying connectivity in the North Sea. Marine Ecology Progress Series 401: 211-220.

Cuveliers, E. L., M. H. D. Larmuseau, B. Hellemans, S. L. N. A. Verherstraeten, F. A. M. Volckaert, \& G. E. Maes, 2012. Multi-marker estimate of genetic connectivity of sole (Solea solea) in the North-East Atlantic Ocean. Marine Biology 159: 1239-1253. 
Degraer, S., E. Verfaillie, W. Willems, E. Adriaens, M. Vincx, \& V. Van Lancker, 2008. Habitat suitability modelling as a mapping tool for macrobenthic communities: An example from the Belgian part of the North Sea. Continental Shelf Research 28: 369-379.

Diopere, E., Cariani, A., Vandamme, S., Van Houdt, J., Tinti, F., Volckaert, F.A.M., FISHPOPTRACE Consortium \& G.E., Maes, 2018. Seascape genetics of a flatfish reveals local selection under high levels of gene flow. ICES Journal of Marine Science 75: 675-689.

Gagliano, M., \& M. I. McCormick, 2004. Feeding history influences otolith shape in tropical fish. Marine Ecology Progress Series 278: 291-296.

Gonzalez-Salas, C., \& P. Lenfant, 2007. Interannual variability and intraannual stability of the otolith shape in European anchovy Engraulis encrasicolus (L.) in the Bay of Biscay. Journal of Fish Biology 70: $35-49$.

Hüssy, K., 2008. Otolith shape in juvenile cod (Gadus morhua): Ontogenetic and environmental effects. Journal of Experimental Marine Biology and Ecology 364: 35-41.

Jung, A., R. Dekker, M. Germain, C. Philippart, J. Witte, \& H. van der Veer, 2017. Long-term shifts in intertidal predator and prey communities in the Wadden Sea and consequences for food requirements and supply. Marine Ecology Progress Series 579: 37-53.

Kaplan, D. M., M. Cuif, C. Fauvelot, L. Vigliola, T. Nguyen-Huu, J. Tiavouane, \& C. Lett, 2017. Uncertainty in empirical estimates of marine larval connectivity. ICES Journal of Marine Science 74: 1723-1734.

Kotoulas, G., F. Bonhomme, \& P. Borsa, 1995. Genetic structure of the common sole Solea vulgaris at different geographic scales. Marine Biology 122: 361-375.

Koubbi, P., C. Loots, G. Cotonnec, X. Harlay, A. Grioche, S. Vaz, C. C. C. U. Martin, M. Walkey, \& A. Carpentier, 2006. Spatial patterns and GIS habitat modelling of Solea solea, Pleuronectes flesus and Limanda limanda fish larvae in the eastern English Channel during the spring. Scientia Marina 147157. 
441

442 Image Processing 18: 236-258.

443

444 155: 223-237. 139-149. 55. 277-281.

Kuhl, F. P., \& C. R. Giardina, 1982. Elliptic Fourier features of a closed contour. Computer Graphics and

Lacroix, G., G. E. Maes, L. J. Bolle, \& F. A. M. Volckaert, 2013. Modelling dispersal dynamics of the early life stages of a marine flatfish (Solea solea L.). Journal of Sea Research 84: 13-25.

Lagardère, F., \& H. Troadec, 1997. Age estimation in common sole Solea solea larvae: validation of daily increments and evaluation of a pattern recognition technique. Marine Ecology Progress Series

Legendre, \& Legendre (eds), 2012. Numerical Ecology, Volume 24 - Elsevier. 1006 pp.

Le Pape, O., F. Chauvet, S. Mahévas, P. Lazure, D. Guérault, \& Y. Désaunay, 2003. Quantitative description of habitat suitability for the juvenile common sole (Solea solea, L.) in the Bay of Biscay (France) and the contribution of different habitats to the adult population. Journal of Sea Research 50:

Le Pape, O., \& N. Cognez, 2016. The range of juvenile movements of estuarine and coastal nursery dependent flatfishes: estimation from a meta-analytical approach. Journal of Sea Research 107: 43-

Lombarte, A., G. J. Torres, \& B. Morales-Nin, 2003. Specific Merluccius otolith growth patterns related to phylogenetics and environmental factors. Journal of the Marine Biological Association of the UK 83:

Lychakov, D. V., \& Y. T. Rebane, 2005. Fish otolith mass asymmetry: morphometry and influence on acoustic functionality. Hearing Research 201: 55-69.

Mahé, K., C. Oudard, T. Mille, J. Keating, P. Gonçalves, L. W. Clausen, G. Petursdottir, H. Rasmussen, E. Meland, E. Mullins, J. K. Pinnegar, Å. Hoines, \& V. M. Trenkel, 2016. Identifying blue whiting (Micromesistius poutassou) stock structure in the Northeast Atlantic by otolith shape analysis. Canadian Journal of Fisheries and Aquatic Sciences 73: 1363-1371. 
465

466

467

468

469

470

471

472

473

474

475

476

477

478

479

480

481

482

483

484

485

486

Mapp, J., E. Hunter, J. Van Der Kooij, S. Songer, \& M. Fisher, 2017. Otolith shape and size: The importance of age when determining indices for fish-stock separation. Fisheries Research 190: 43-52.

Mérigot, B., Y. Letourneur, \& R. Lecomte-Finiger, 2007. Characterization of local populations of the common sole Solea solea (Pisces, Soleidae) in the NW Mediterranean through otolith morphometrics and shape analysis. Marine Biology 151: 997-1008.

Mille, T., K. Mahé, M. C. Villanueva, H. De Pontual, \& B. Ernande, 2015. Sagittal otolith morphogenesis asymmetry in marine fishes. Journal of Fish Biology 87: 646-663.

Morat, F., 2011. Influence des apports rhodaniens sur les traits d'histoire de vie de la sole commune (Solea solea) : apports de l'étude minéralogique et chimique des otolithes. Thèse de doctorat, spécialité Océanographie, Université Aix Marseille II, Marseille, France, 308 pp

Morat, F., Gibert, P., Reynaud, N., Testi, B., Favriou, P., Raymond, V., Carrel, G. \& Maire, A., 2017. Spatial distribution, total length frequencies and otolith morphometry as tools to analyse the effects of a flash flood on populations of roach (Rutilus rutilus). Ecology of Freshwater Fish 27: 421-432.

Morat, F., Y. Letourneur, J. Dierking, C. Pécheyran, G. Bareille, D. Blamart, \& M. Harmelin-Vivien, 2014. The great melting pot. Common sole population connectivity assessed by otolith and water fingerprints. PLOS ONE 9 (1): e86585.

OSPAR Commission (eds), 2000. Region 2: Greater North Sea. London.

Neves, V., D. Silva, F. Martinho, C. Antunes, S. Ramos, \& V. Freitas, 2018. Assessing the effects of internal and external acoustic tagging methods on European flounder Platichthys flesus. Fisheries Research 206: 202-208.

Pawson, M. G., \& S. Jennings, 1996. A critique of methods for stock identification in marine capture fisheries. Fisheries Research 25: 203-217. 
487

488

489

490

491

492

493

494

495

496

497

498

499

500

501

502

503

504

505

506

507

508

509

Pinsky, M. L., P. Saenz-Agudelo, O. C. Salles, G. R. Almany, M. Bode, M. L. Berumen, S. Andréfouët, S. R. Thorrold, G. P. Jones, \& S. Planes, 2017. Marine dispersal scales are congruent over evolutionary and ecological time. Current Biology 27: 149-154.

R development core team. 2011. R: A language and environment for statistical computing. $R$ Foundation for Statistical Computing, Vienna, Austria.

Rabaut, M., M. Audfroid Calderón, L. Van de Moortel, J. van Dalfsen, M. Vincx, S. Degraer, \& N. Desroy, 2013. The role of structuring benthos for juvenile flatfish. Journal of Sea Research 84: 70-76.

Rohlf, F. J., \& J. W. Archie, 1984. A comparison of Fourier methods for the description of wing shape in mosquitoes (Diptera: Culicidae). Systematic Biology 33: 302-317.

Russell, F. S. (eds), 1976. The eggs and planktonic stages of British marine fishes. Academic Press, London, New York, 524 pp.

Thorrold, S. R., C. Latkoczy, P. K. Swart, \& C. M. Jones, 2001. Natal homing in a marine fish metapopulation. Science (New York, N.Y.) 291: 297-299.

Tuset, V. M., I. J. Lozano, J. A. González, J. F. Pertusa, \& M. M. García-Díaz, 2003. Shape indices to identify regional differences in otolith morphology of comber, Serranus cabrilla (L., 1758). Journal of Applied Ichthyology 19: 88-93.

Van der Land, M. A., 1991. Distribution of flatfish eggs in the 1989 egg surveys in the southeastern North Sea, and mortality of plaice and sole eggs. Netherlands Journal of Sea Research 27: 277-286.

Van der Veer, H., J. Koot, G. Aarts, R. Dekker, W. Diderich, V. Freitas, \& J. Witte, 2011. Long-term trends in juvenile flatfish indicate a dramatic reduction in nursery function of the Balgzand intertidal, Dutch Wadden Sea. Marine Ecology Progress Series 434: 143-154.

Van Hoey, G., S. Degraer, \& M. Vincx, 2004. Macrobenthic community structure of soft-bottom sediments at the Belgian Continental Shelf. Estuarine, Coastal and Shelf Science 59: 599-613. 
510 Vieira, A. R., A. Neves, V. Sequeira, R. B. Paiva, \& L. S. Gordo, 2014. Otolith shape analysis as a tool for

511 stock discrimination of forkbeard (Phycis phycis) in the Northeast Atlantic. Hydrobiologia 728: 103512110.

513 Vignon, M., \& F. Morat, 2010. Environmental and genetic determinant of otolith shape revealed by a 514 non-indigenous tropical fish. Marine Ecology-progress Series 411: 231-241. 


\section{Tables}

Table 1: Number of fish analyzed per station and per nursery (Belgian coast and Wadden Sea), including the date of capture, GPS coordinates, name of sampling survey (Demersal Young Fish Survey, DYFS, and B-FishConnect) and the sea surface temperature at the time of sampling are given

\begin{tabular}{|c|c|c|c|c|c|c|c|c|}
\hline Year & Area & $\begin{array}{l}\text { Coast } \\
\text { side }\end{array}$ & Station & $\begin{array}{c}\text { Sample } \\
\text { size }\end{array}$ & Sampling date & $\begin{array}{c}\text { GPS } \\
\text { coordinates }\end{array}$ & $\begin{array}{c}\text { Sea surface } \\
\text { temperature } \\
\left({ }^{\circ} \mathrm{C}\right)\end{array}$ & Survey \\
\hline \multirow[t]{8}{*}{2013} & Belgium & West & OOST & 14 & $28 / 08 / 2013$ & $51.23 \mathrm{~N}, 2.80 \mathrm{E}$ & 19.3 & B-FishConnect \\
\hline & & & ST16 & 30 & $10 / 09 / 2013$ & $51.19 \mathrm{~N}, 2.70 \mathrm{E}$ & 18.8 & DYFS \\
\hline & & East & ST09 & 33 & $09 / 09 / 2013$ & $51.35 \mathrm{~N}, 3.00 \mathrm{E}$ & 19.5 & DYFS \\
\hline & & & ST05 & 33 & $12 / 09 / 2013$ & $51.45 \mathrm{~N}, 3.01 \mathrm{E}$ & 17.7 & B-FishConnect \\
\hline & & & ST37 & 29 & $12 / 09 / 2013$ & $51.48 \mathrm{~N}, 3.14 \mathrm{E}$ & 17.8 & DYFS \\
\hline & & & ST06 & 14 & $13 / 09 / 2013$ & $51.38 \mathrm{~N}, 2.85 \mathrm{E}$ & 17.7 & DYFS \\
\hline & & & FTO2 & 20 & $24 / 09 / 2013$ & $51.43 \mathrm{~N}, 3.31 \mathrm{E}$ & 16.9 & DYFS \\
\hline & & & Total & 173 & & & & \\
\hline \multirow[t]{7}{*}{2014} & Belgium & West & ST23 & 30 & $15 / 09 / 2014$ & $51.13 \mathrm{~N}, 2.70 \mathrm{E}$ & 18.1 & DYFS \\
\hline & & East & ST09 & 27 & $16 / 09 / 2014$ & $51.35 \mathrm{~N}, 3.00 \mathrm{E}$ & 18.5 & DYFS \\
\hline & & & FT01 & 23 & $10 / 10 / 2014$ & $51.35 \mathrm{~N}, 3.10 \mathrm{E}$ & 16.9 & B-FishConnect \\
\hline & & & Total & 80 & & & & \\
\hline & Wadden & & NL01 & 34 & $16 / 09 / 2014$ & $53.48 \mathrm{~N}, 6.49 \mathrm{E}$ & 18.2 & DYFS \\
\hline & Sea & & NLO2 & 27 & $23 / 09 / 2014$ & $53.35 \mathrm{~N}, 6.97 \mathrm{E}$ & 18.1 & DYFS \\
\hline & & & Total & 61 & & & & \\
\hline
\end{tabular}


Table 2: Summary of the mean value of the shape indices (form-factor, ellipticity and roundness) per size class for each dataset ( $n=173$ for BE2013, $n=80$ for BE2014, $n=61$ for NL2014) and comparisons of each shape index between the three different size classes (L1, L2 and L3) for each dataset and for the comparisons of all age- 0 sole together at the regional (Belgian vs. Wadden Sea nursery) $(n=141)$ and at the local scale (Belgian 2013 vs. 2014) $(n=253)$, including the significance level

\begin{tabular}{lccccccc}
\hline Shape indices & Datasets & $\begin{array}{c}\text { L1 } \\
(52-76 \mathrm{~mm})\end{array}$ & $\begin{array}{c}\text { L2 } \\
(76-82 \mathrm{~mm})\end{array}$ & $\begin{array}{c}\text { L3 } \\
(82-102 \mathrm{~mm})\end{array}$ & $\begin{array}{c}\text { L1-L2-L3 } \\
P \text { value }\end{array}$ & All sizes & $P$ value \\
\hline Form-factor & BE2013 & 0.876 & 0.871 & 0.864 & $<0.001$ & & \\
& BE2014 & 0.883 & 0.879 & 0.865 & $<0.001$ & NL vs BE 2014 & $<0.001$ \\
& NL2014 & 0.874 & 0.860 & 0.855 & $<0.01$ & & \\
Ellipticity & & & & & & BE 2013 vs 2014 & $<0.01$ \\
& BE2013 & 0.039 & 0.043 & 0.048 & 0.016 & NL vs BE 2014 & 0.723 \\
& BE2014 & 0.034 & 0.038 & 0.047 & 0.012 & & \\
& NL2014 & 0.042 & 0.036 & 0.037 & 0.122 & BE 2013 vs 2014 & 0.042 \\
& & & & & & & \\
Roundness & BE2013 & 0.947 & 0.946 & 0.939 & 0.354 & NL vs BE 2014 & 0.807 \\
& BE2014 & 0.961 & 0.960 & 0.943 & 0.081 & & \\
& NL2014 & 0.946 & 0.958 & 0.953 & 0.102 & BE 2013 vs 2014 & 0.005 \\
\hline
\end{tabular}


Table 3: Summary of partial redundancy analysis (pRDA) for asymmetry $(n=314)$ and for spatiotemporal variations at the regional scale (Belgian vs. Wadden Sea nursery) $(n=141)$ and at the local scale (eastern vs. western coastal zones of the Belgian nursery and 2013 vs. 2014) ( $n=253)$. Degrees of freedom (df), significance values and the variance explained by each variable $\left(R^{2}\right)$ are included

\begin{tabular}{|c|c|c|c|c|}
\hline Hypothesis & Factors & df & $P$ value & $\mathrm{R}^{2}$ adjusted $(\%)$ \\
\hline Asymmetry: all otoliths & Otolith_side & 1 & 0.01 & 5.8 \\
\hline \multirow[t]{3}{*}{ Regional differences: NL-BE 2014} & Nursery & 1 & 0.04 & 0.6 \\
\hline & Sampling date & 1 & 0.41 & $<0$ \\
\hline & SST & 1 & 0.49 & $<0$ \\
\hline \multirow[t]{4}{*}{ Local differences: BE 2013-2014 } & Year & 1 & 0.08 & $<0$ \\
\hline & Sampling date & 1 & 0.34 & $<0$ \\
\hline & $\begin{array}{c}\text { East / West } \\
\text { coastal regions }\end{array}$ & 1 & 0.70 & $<0$ \\
\hline & SST & 1 & 0.19 & $<0$ \\
\hline
\end{tabular}




\section{Figure captions}

Figure 1: Map of the sampling stations of age-0 sole on the Belgian and the Wadden Sea nursery grounds in 2013 and 2014

Figure 2: Boxplot of form-factor (a) and ellipticity (b) for 314 age-0 sole juveniles of sole of three size classes for each dataset ( $n=173$ for BE2013, $n=80$ for BE2014, $n=61$ for NL2014)

Figure 3: Reconstruction of average sagittal otolith shape for 314 age- 0 sole based on Elliptic Fourier Descriptors as a function of (a) otolith side (left dotted vs. right full line); (b) geography (Belgian nursery dotted vs. Wadden Sea full line); and (c) PCA clustering (Cluster 1 dotted vs. Cluster 2 full line see Figure 4 for the clusters). Non-overlapping regions of the otolith have been crosshatched to show differences between otolith shape

Figure 4: Principal Component Analysis of Fourier coefficients of otoliths of juvenile sole at (a) the regional scale (Belgian coast $(\bullet)$ vs. Wadden Sea nursery grounds $(\Delta)$ ), and $(\mathbf{b})$ at the local Belgian scale for the year 2013 (0) vs. $2014(\bullet)$

Figure 5: Size distribution of the standard length (in $\mathrm{mm}$ ) of the two clusters of sole sampled in 2014 on the Wadden Sea and Belgian nursery grounds (a) and on the Belgian nursery in 2013 and 2014 (b). The average standard length was significantly different between the two clusters (as indicated by the star in a) for the nursery comparison while it was not significantly (n.s.) different between the two clusters on the Belgian nursery (b) 


\section{Supplementary material}

Figure S1: Cluster dendrogram of the similarity distances of the Fourier coefficients of ten randomly chosen otoliths of juvenile sole, based on Ward's distance. Picture numbers range from 1 to 40, with four consecutive pictures (e.g. 1-4, 5-8, etc.) being from the same otolith

Figure S2: Boxplot of roundness for 314 age-0 sole juveniles of sole at three size classes for each dataset (BE2013, BE2014 and NL2014)

Figure S3: Cluster dendrogram of the similarity distances of the Fourier coefficients of the juvenile sole sampled at the Belgian and Wadden Sea nursery grounds in 2014 (a) and at the Belgian nursery in 2013 and 2014 (b) using a complete hierarchical clustering method, based on Ward's distance 


\section{Figures}

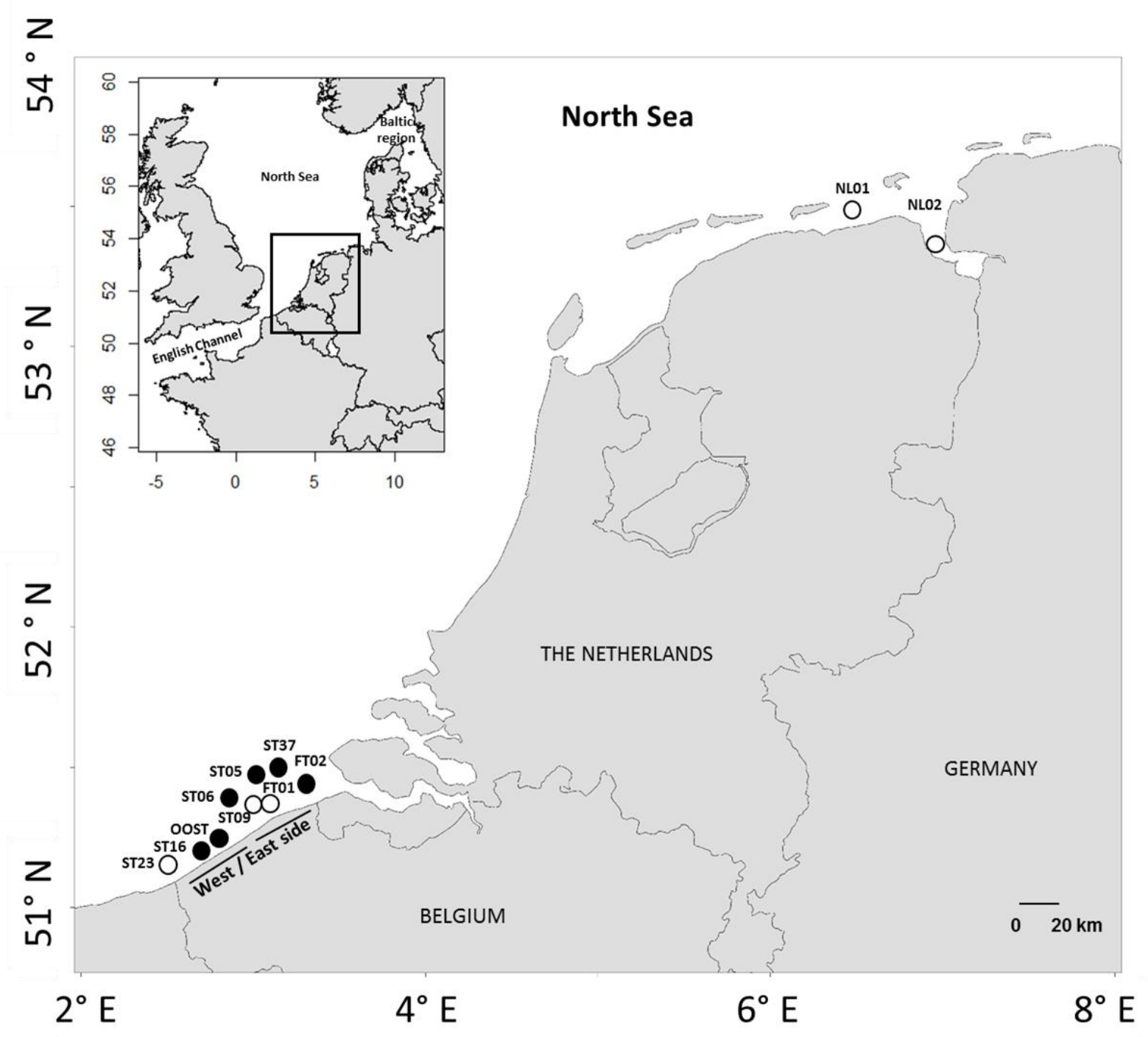

Figure 1: Map of the sampling stations of age-0 sole on the Belgian and the Wadden Sea nursery grounds in 2013 and 2014 

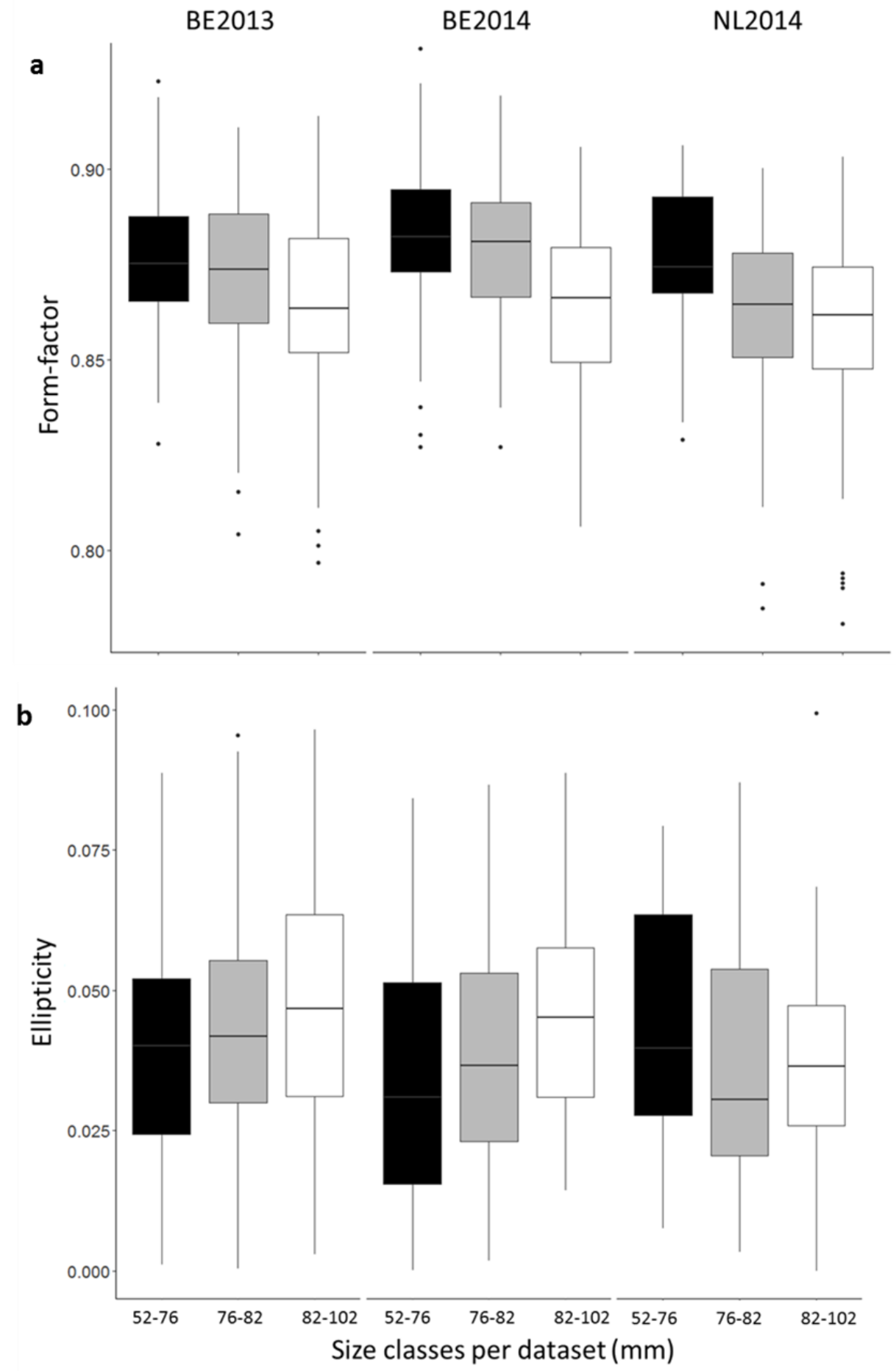

Figure 2: Boxplot of form-factor (a) and ellipticity (b) for 314 age-0 sole juveniles of sole of three size classes for each dataset ( $n=173$ for BE2013, $n=80$ for BE2014, $n=61$ for NL2014) 

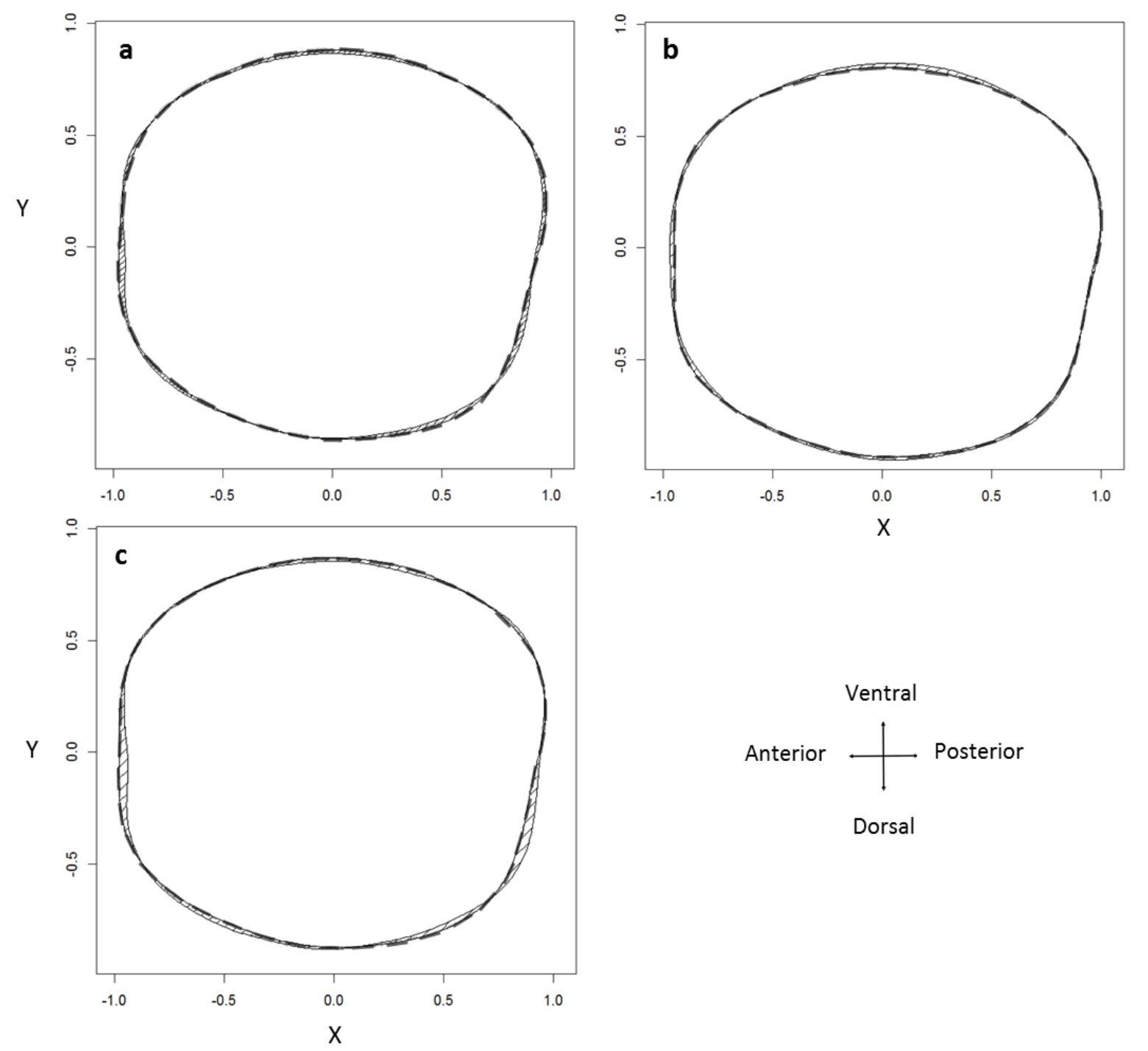

Figure 3: Reconstruction of average sagittal otolith shape for 314 age-0 sole based on Elliptic Fourier Descriptors as a function of (a) otolith side (left dotted vs. right full line); (b) geography (Belgian nursery dotted vs. Wadden Sea full line); and (c) PCA clustering (Cluster 1 dotted vs. Cluster 2 full line see Figure 4 for the clusters). Non-overlapping regions of the otolith have been crosshatched to show differences between otolith shape 
a

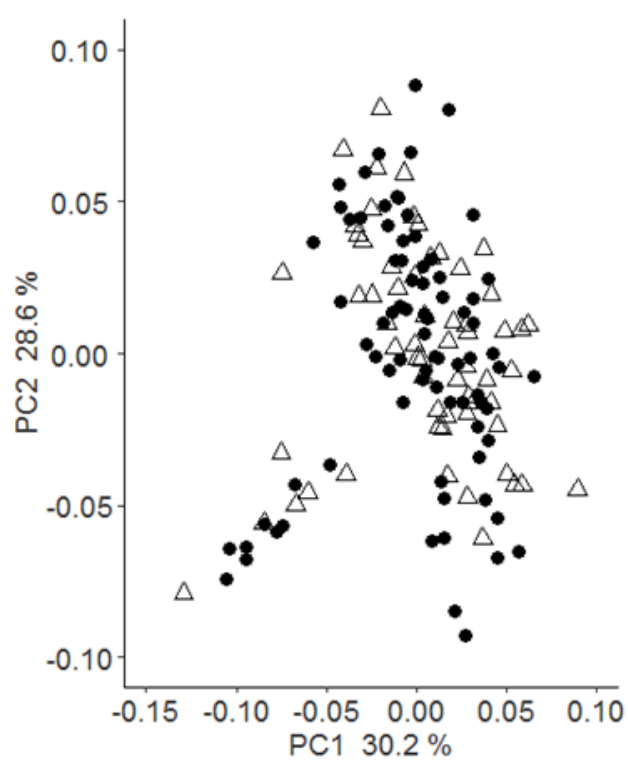

b

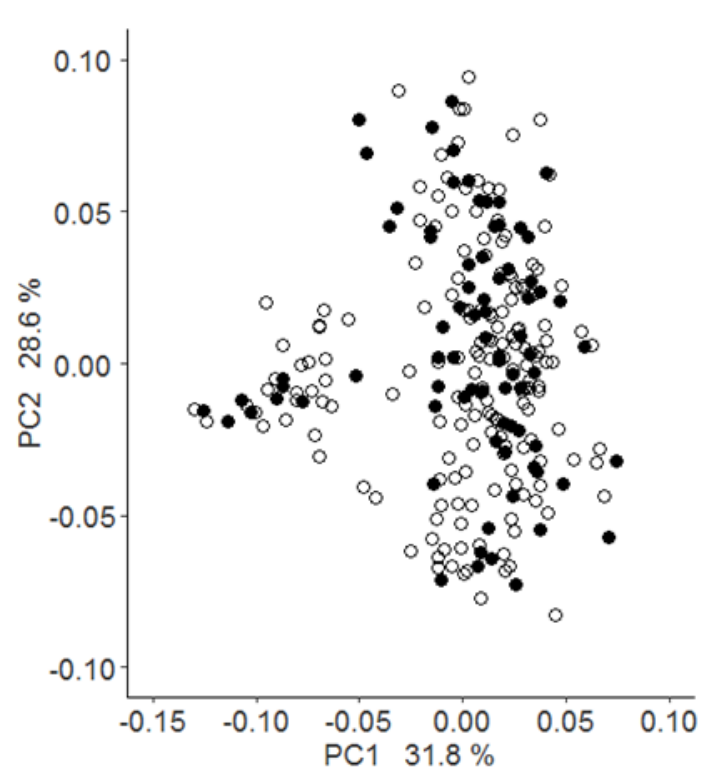

Figure 4: Principal Component Analysis of Fourier coefficients of otoliths of juvenile sole at (a) the regional scale (Belgian coast $(\bullet)$ vs. Wadden Sea nursery grounds $(\Delta)$ ), and $(\mathbf{b})$ at the local Belgian scale for the year 2013 (o) vs. $2014(\bullet)$ 
a) NL vs BE 2014

$*$

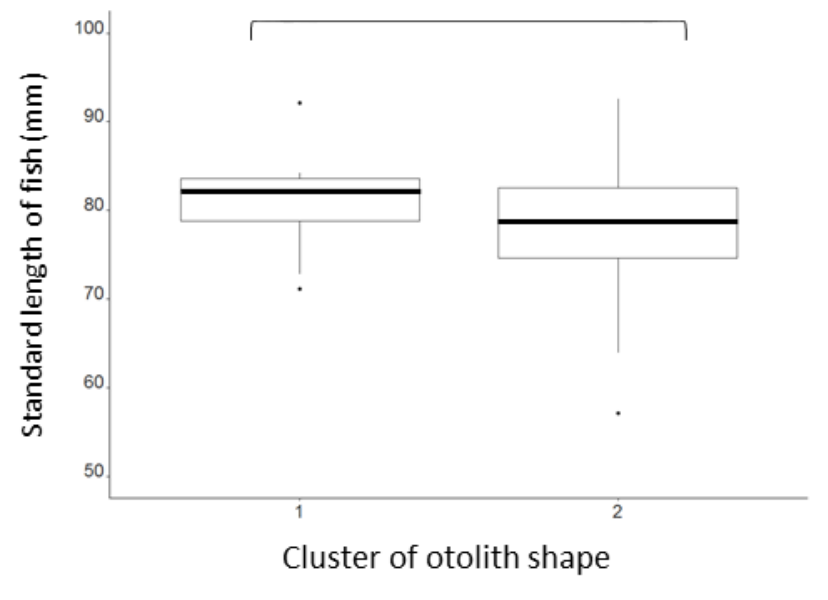

b) BE 2013-2014

n.s.

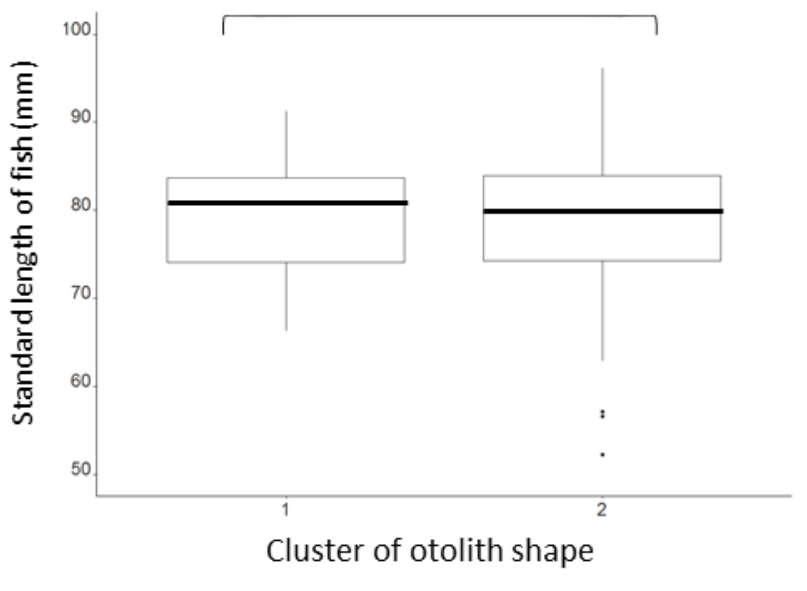

Figure 5: Size distribution of the standard length (in $\mathrm{mm}$ ) of the two clusters of sole sampled in 2014 on the Wadden Sea and Belgian nursery grounds (a) and on the Belgian nursery in 2013 and 2014 (b). The average standard length was significantly different between the two clusters (as indicated by the star in a) for the nursery comparison while it was not significantly (n.s.) different between the two clusters on the Belgian nursery (b) 
Table 1: Number of fish analyzed per station and per nursery (Belgian coast and Wadden Sea), including the date of capture, GPS coordinates, name of sampling survey (Demersal Young Fish Survey, DYFS, and B-FishConnect) and the sea surface temperature at the time of sampling are given

\begin{tabular}{|c|c|c|c|c|c|c|c|c|}
\hline Year & Area & $\begin{array}{l}\text { Coast } \\
\text { side }\end{array}$ & Station & $\begin{array}{l}\text { Sample } \\
\text { size }\end{array}$ & Sampling date & $\begin{array}{c}\text { GPS } \\
\text { coordinates }\end{array}$ & $\begin{array}{c}\text { Sea surface } \\
\text { temperature } \\
\left({ }^{\circ} \mathrm{C}\right)\end{array}$ & Survey \\
\hline \multirow[t]{8}{*}{2013} & Belgium & West & OOST & 14 & 28/08/2013 & $51.23 \mathrm{~N}, 2.80 \mathrm{E}$ & 19.3 & B-FishConnect \\
\hline & & & ST16 & 30 & 10/09/2013 & $51.19 \mathrm{~N}, 2.70 \mathrm{E}$ & 18.8 & DYFS \\
\hline & & East & STO9 & 33 & 09/09/2013 & $51.35 \mathrm{~N}, 3.00 \mathrm{E}$ & 19.5 & DYFS \\
\hline & & & ST05 & 33 & $12 / 09 / 2013$ & $51.45 \mathrm{~N}, 3.01 \mathrm{E}$ & 17.7 & B-FishConnect \\
\hline & & & ST37 & 29 & $12 / 09 / 2013$ & $51.48 \mathrm{~N}, 3.14 \mathrm{E}$ & 17.8 & DYFS \\
\hline & & & STO6 & 14 & $13 / 09 / 2013$ & $51.38 \mathrm{~N}, 2.85 \mathrm{E}$ & 17.7 & DYFS \\
\hline & & & FTO2 & 20 & $24 / 09 / 2013$ & $51.43 \mathrm{~N}, 3.31 \mathrm{E}$ & 16.9 & DYFS \\
\hline & & & Total & 173 & & & & \\
\hline \multirow[t]{7}{*}{2014} & Belgium & West & ST23 & 30 & 15/09/2014 & $51.13 \mathrm{~N}, 2.70 \mathrm{E}$ & 18.1 & DYFS \\
\hline & & East & ST09 & 27 & 16/09/2014 & $51.35 \mathrm{~N}, 3.00 \mathrm{E}$ & 18.5 & DYFS \\
\hline & & & FT01 & 23 & 10/10/2014 & $51.35 \mathrm{~N}, 3.10 \mathrm{E}$ & 16.9 & B-FishConnect \\
\hline & & & Total & 80 & & & & \\
\hline & Wadden & & NL01 & 34 & $16 / 09 / 2014$ & $53.48 \mathrm{~N}, 6.49 \mathrm{E}$ & 18.2 & DYFS \\
\hline & Sea & & NL02 & 27 & 23/09/2014 & $53.35 \mathrm{~N}, 6.97 \mathrm{E}$ & 18.1 & DYFS \\
\hline & & & Total & 61 & & & & \\
\hline
\end{tabular}


Table 2: Summary of the mean value of the shape indices (form-factor, ellipticity and roundness) per size class for each dataset ( $n=173$ for BE2013, $n=80$ for BE2014, $n=61$ for NL2014) and comparisons of each shape index between the three different size classes (L1, L2 and L3) for each dataset and for the comparisons of all age- 0 sole together at the regional (Belgian vs. Wadden Sea nursery) $(n=141)$ and at the local scale (Belgian 2013 vs. 2014) $(n=253)$, including the significance level

\begin{tabular}{lccccccc}
\hline Shape indices & Datasets & $\begin{array}{c}\text { L1 } \\
(52-76 \mathrm{~mm})\end{array}$ & $\begin{array}{c}\text { L2 } \\
(76-82 \mathrm{~mm})\end{array}$ & $\begin{array}{c}\text { L3 } \\
(82-102 \mathrm{~mm})\end{array}$ & $\begin{array}{c}\text { L1-L2-L3 } \\
P \text { value }\end{array}$ & All sizes & $P$ value \\
\hline Form-factor & BE2013 & 0.876 & 0.871 & 0.864 & $<0.001$ & \multirow{2}{*}{ NL vs BE 2014 } & $<0.001$ \\
& BE2014 & 0.883 & 0.879 & 0.865 & $<0.001$ & & \\
& NL2014 & 0.874 & 0.860 & 0.855 & $<0.01$ & BE 2013 vs 2014 & $<0.01$ \\
& & & & & & & \\
Ellipticity & BE2013 & 0.039 & 0.043 & 0.048 & 0.016 & NL vs BE 2014 & 0.723 \\
& BE2014 & 0.034 & 0.038 & 0.047 & 0.012 & & \\
& NL2014 & 0.042 & 0.036 & 0.037 & 0.122 & BE 2013 vs 2014 & 0.042 \\
& & & & & & & \\
Roundness & BE2013 & 0.947 & 0.946 & 0.939 & 0.354 & NL vs BE 2014 & 0.807 \\
& BE2014 & 0.961 & 0.960 & 0.943 & 0.081 & & \\
& NL2014 & 0.946 & 0.958 & 0.953 & 0.102 & BE 2013 vs 2014 & 0.005 \\
\hline
\end{tabular}


Table 3: Summary of partial redundancy analysis $(\mathrm{pRDA})$ for asymmetry $(n=314)$ and for spatiotemporal variations at the regional scale (Belgian vs. Wadden Sea nursery) $(n=141)$ and at the local scale (eastern vs. western coastal zones of the Belgian nursery and 2013 vs. 2014) ( $n=253$ ). Degrees of freedom (df), significance values and the variance explained by each variable $\left(R^{2}\right)$ are included

\begin{tabular}{|c|c|c|c|c|}
\hline Hypothesis & Factors & $\mathrm{df}$ & $\begin{array}{c}P \\
\text { value }\end{array}$ & $\begin{array}{c}R^{2} \text { adjusted } \\
(\%)\end{array}$ \\
\hline Asymmetry: all otoliths & Otolith_side & 1 & 0.01 & 5.8 \\
\hline \multirow[t]{3}{*}{ Regional differences: NL-BE 2014} & Nursery & 1 & 0.04 & 0.6 \\
\hline & Sampling date & 1 & 0.41 & $<0$ \\
\hline & SST & 1 & 0.49 & $<0$ \\
\hline \multirow[t]{4}{*}{ Local differences: BE 2013-2014 } & Year & 1 & 0.08 & $<0$ \\
\hline & Sampling date & 1 & 0.34 & $<0$ \\
\hline & $\begin{array}{c}\text { East / West } \\
\text { coastal regions }\end{array}$ & 1 & 0.70 & $<0$ \\
\hline & SST & 1 & 0.19 & $<0$ \\
\hline
\end{tabular}




\section{Supplementary material}

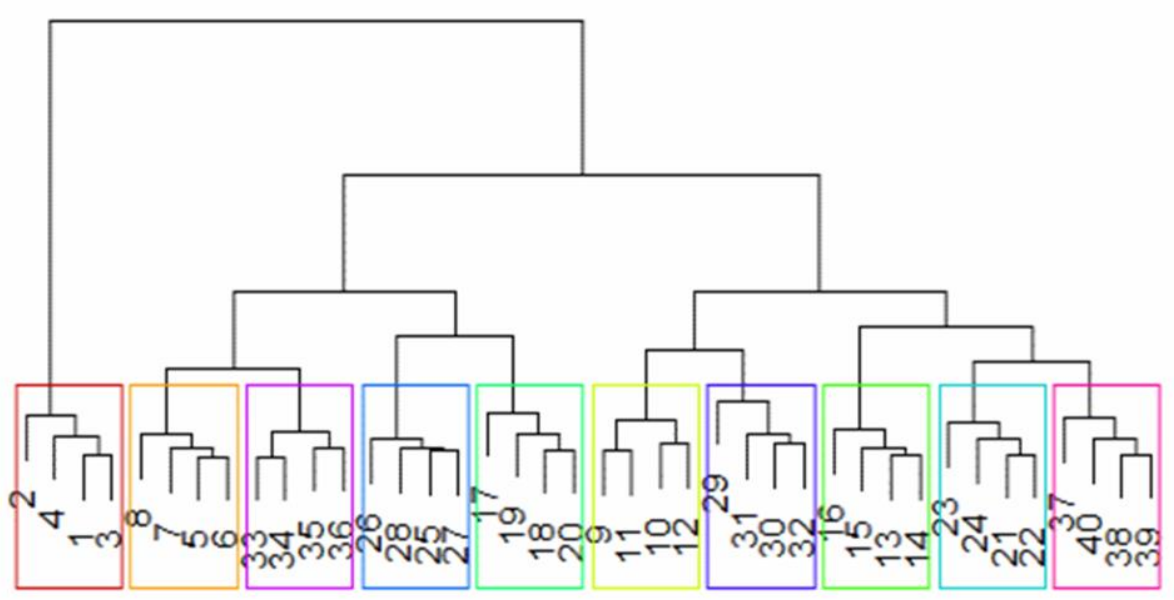

Figure S1: Cluster dendrogram of the similarity distances of the Fourier coefficients of ten randomly chosen otoliths of juvenile sole, based on Ward's distance. Picture numbers range from 1 to 40, with four consecutive pictures (e.g. 1-4, 5-8, etc.) being from the same otolith 


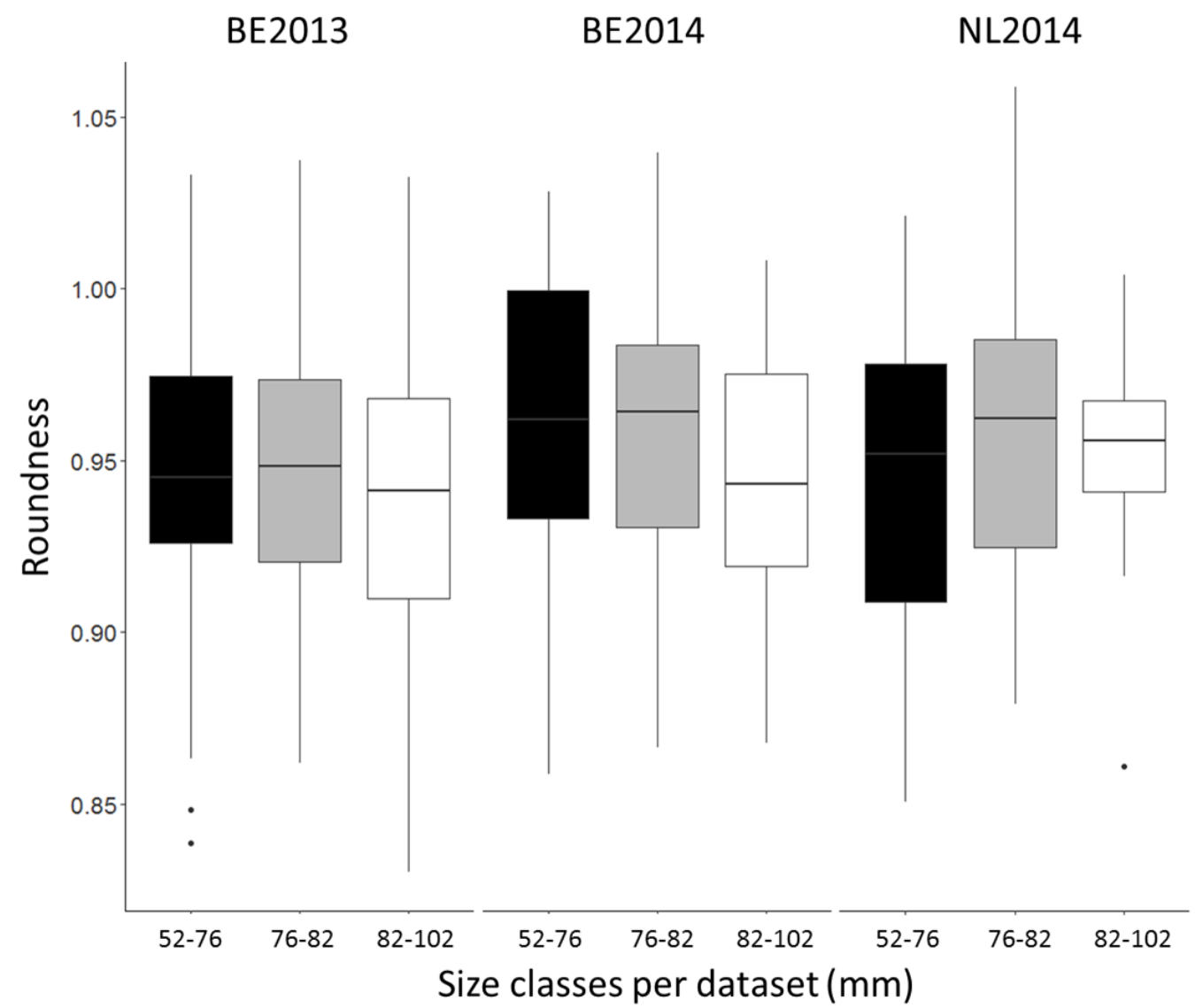

Figure S2: Boxplot of roundness for 314 age-0 sole juveniles of sole at three size classes for each dataset (BE2013, BE2014 and NL2014) 

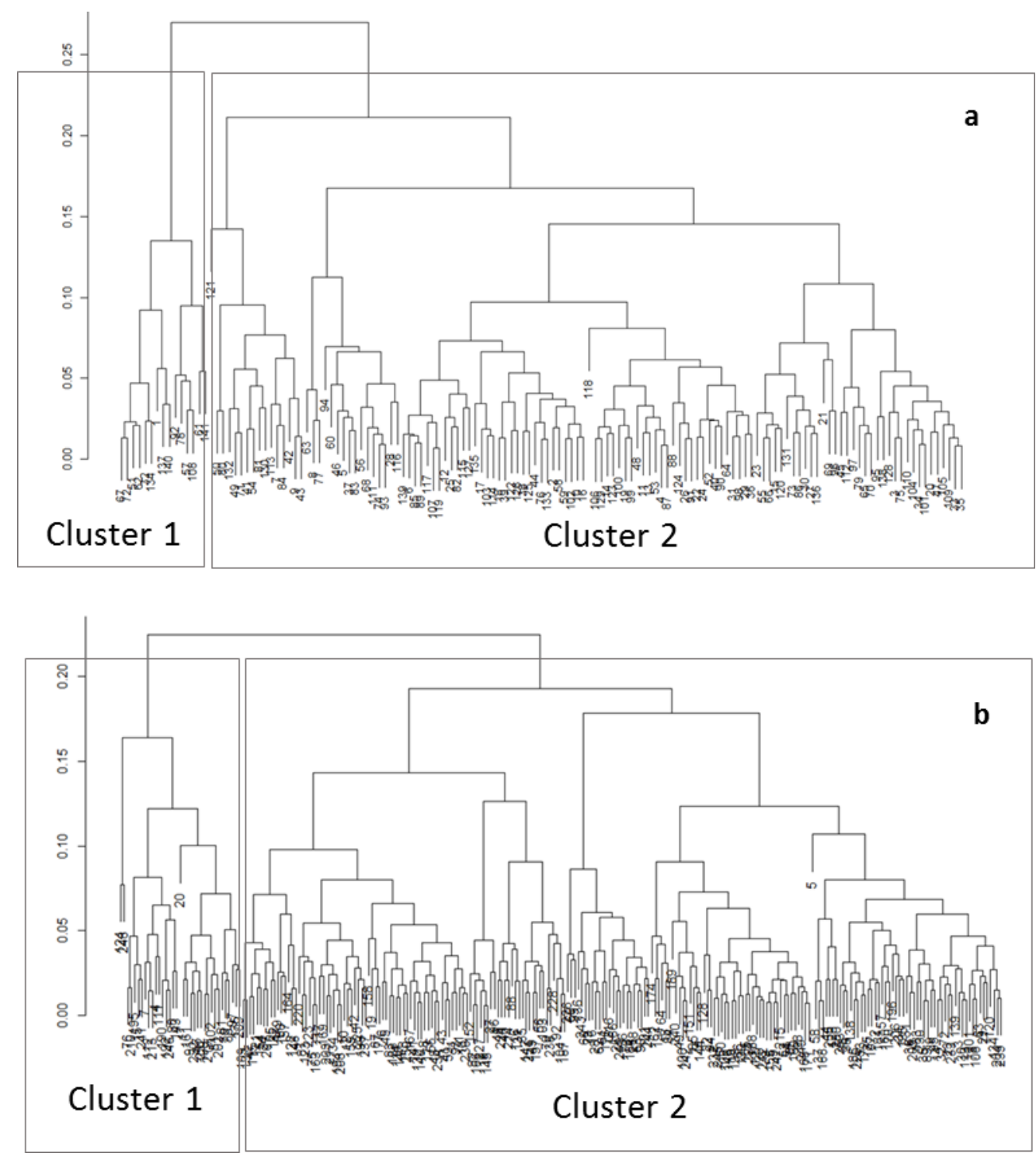

Figure S3: Cluster dendrogram of the similarity distances of the Fourier coefficients of the juvenile sole sampled at the Belgian and Wadden Sea nursery grounds in 2014 (a) and at the Belgian nursery in 2013 and 2014 (b) using a complete hierarchical clustering method, based on Ward's distance 